Keywords: endometrial cancer; atypical endometrial hyperplasia; metformin; Ki-67; PI3K-AKT-mTOR phosphoproteins; presurgical window study

\title{
Measuring the biological effect of presurgical metformin treatment in endometrial cancer
}

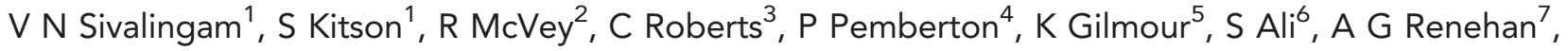 \\ H C Kitchener ${ }^{1}$ and E J Crosbie ${ }^{\star}, 1$ \\ ${ }^{1}$ Gynaecological Oncology Research Group, Institute of Cancer Sciences, University of Manchester, St Mary's Hospital, Oxford \\ Road, Manchester M13 9WL, UK; ${ }^{2}$ Department of Histopathology, Central Manchester University Hospitals NHS Foundation Trust, \\ Manchester, UK; ${ }^{3}$ Centre for Biostatistics, Institute of Population Health, University of Manchester, Manchester, UK; ${ }^{4} \mathrm{Clinical}$ \\ Biochemistry Department, Central Manchester University Hospitals NHS Foundation Trust, Manchester, UK; ${ }^{5}$ Obstetrics and \\ Gynaecology Department, Tameside General Hospital, Tameside, UK; ${ }^{6}$ Obstetrics and Gynaecology Department, The Royal \\ Oldham Hospital, Pennine Acute Hospitals NHS Trust, Oldham, UK and ${ }^{7}$ Cancer Studies and Surgery Research Group, Institute of \\ Cancer Sciences, University of Manchester, Manchester, UK
}

Background: Preclinical studies in endometrial cancer (EC) show that metformin reduces cellular proliferation by PI3K-AKT-mTOR inhibition. We tested the hypothesis that short-term presurgical metformin reduces cellular proliferation in atypical endometrial hyperplasia (AEH) and endometrioid EC, and assessed the feasibility of using phosphorylated PI3K-AKT-mTOR proteins as tissue end points.

Methods: Women with AEH or EC received metformin $850 \mathrm{mg}$ twice a day or no drug in the presurgical window between diagnosis and hysterectomy. Before and after the window, tissue samples were obtained; serum markers of insulin resistance (e.g. homeostasis model of assessment of insulin resistance index) were determined; and anthropometrics measured (e.g. BMI). Cell proliferation (Ki-67) and PI3K-AKT-mTOR phosphostatus were assessed by immunohistochemistry and scored blinded to treatment.

Results: Twenty-eight metformin-treated and 12 untreated patients, well matched for age and BMl, completed the study. Metformin treatment (median 20 days, range 7-34) was associated with a $17.2 \%$ reduction in tumour $\mathrm{Ki}-67(95 \% \mathrm{Cl}-27.4,-7.0$, $P=0.002$ ), in a dose-dependent manner. Tumour PI3K-AKT-mTOR protein phosphostatus varied but the effects were not significant after adjusting for changes in controls.

Conclusions: Short-term metformin was associated with reduced Ki-67 expression in EC. Changes in tumour PI3K-AKT-mTOR protein phosphostatus were seen in both groups. Future studies should address the variability attributed to different sampling techniques including devascularisation of the uterus at hysterectomy.

The incidence of endometrial cancer (EC) is rising (Cancer Research UK, 2014). A major contributor to this rise is the obesity epidemic. Worldwide, the proportion of women with a BMI of $25 \mathrm{~kg} \mathrm{~m}^{-2}$ or greater has increased from $30 \%$ to $38 \%$ over a 30 year period ( $\mathrm{Ng}$ et al, 2014), and as many as $34 \%$ of all ECs are directly attributable to patients being overweight or obese (Arnold et al, 2015). Endometrial cancer ranks highest among all cancers in its association with obesity, with every $5 \mathrm{~kg} \mathrm{~m}^{-2}$ increase in BMI conferring a 1.6-fold increased risk of the disease (Renehan et al, 2008; Crosbie et al, 2010). Women with type 2 diabetes mellitus (T2DM) have a two-fold increased risk of EC compared with nondiabetic women (Friberg et al, 2007), and a prospective study found up to $36 \%$ of patients with EC have undiagnosed insulin resistance (Burzawa et al, 2011). The mechanisms underpinning

*Correspondence: Dr E Crosbie; E-mail. emma.crosbie@manchester.ac.uk

Received 4 September 2015; revised 26 November 2015; accepted 2 December 2015; published online 21 January 2016

(c) 2016 Cancer Research UK. All rights reserved 0007-0920/16

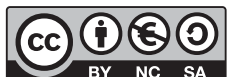

B) $C \cap$ 
this link between obesity, insulin resistance and endometrial carcinogenesis are incompletely understood.

Metformin is first-line medical therapy for T2DM. Epidemiological data have suggested that diabetic patients taking metformin have a lower incidence of cancer compared with those taking other hypoglycaemic agents (Evans et al, 2005; Libby et al, 2009). Preclinical studies have demonstrated a growth static effect of metformin on breast, prostate, ovarian and EC cell lines, effected both through alterations in glucose metabolism and inhibition of the PI3K-AKT-mTOR signalling pathway (Zakikhani et al, 2006, 2010; Cantrell et al, 2010; Sarfstein et al, 2013). Metformin accumulates in the tumour tissue and activates AMPK, an inhibitor of the mTOR pathway (Zakikhani et al, 2006). The impact of metformin on tumour growth has been assessed in vivo using presurgical window studies, where expression of the proliferation marker Ki-67 is measured before and after treatment with metformin in patients awaiting breast (Hadad et al, 2011; Bonanni et al, 2012; Niraula et al, 2012), prostate (Joshua et al, 2014) and EC surgery (Laskov et al, 2014; Mitsuhashi et al, 2014; Schuler et al, 2015). Three previous studies (Laskov et al, 2014; Mitsuhashi et al, 2014; Schuler et al, 2015) report that metformin administration reduced $\mathrm{Ki}-67$ expression in endometrial tumours when given for 2-4 weeks before hysterectomy, but all three lacked a contemporaneous control group, and thus one cannot conclusively attribute these changes to metformin.

As a long-term strategy, we wish to develop large trials using metformin in the pre- or postoperative setting in women with EC. Measurement of tumour Ki-67 expression is a useful and readily performed surrogate biomarker assay, but it is nonspecific. The putative cancer-relevant cellular mechanism for metformin offers an opportunity to include tumour biomarkers, such as phospho4EBP-1 expression, as surrogates of response, but interpretation in human studies is not trivial, and is confounded by many factors, including sample timing in relation to drug administration and tissue handling. Our long-term aim is to test the hypothesis that metformin has a growth inhibitory effect in EC. Given the potential pitfalls listed above, in the present study, our aim was first to establish that metformin is well tolerated in this oncological setting, and then test the hypothesis that short-term metformin use reduces cellular proliferation in women with atypical endometrial hyperplasia $(\mathrm{AEH})$ and endometrioid EC, and additionally assess the feasibility of using related phosphorylated PI3K-AKT-mTOR proteins as tumour end points.

\section{MATERIALS AND METHODS}

Clinical trial study design. This was a non-randomised trial of metformin or no drug taken during the presurgical window period between diagnosis and hysterectomy. Women with biopsy-proven $\mathrm{AEH}$ or endometrioid EC scheduled for hysterectomy were eligible to take part. Women with diabetes on hypoglycaemic medication, those with non-endometrioid histology and those on concomitant progesterone therapy were excluded from the study. Women in the metformin group received metformin $850 \mathrm{mg}$ twice daily for 7 to 30 days until the evening before hysterectomy. Women who declined metformin, whose window period was too short $(<7$ days) or whose renal function was impaired (eGFR $<45 \mathrm{ml} \mathrm{min}^{-1}$ per 1.732 ) were recruited to the control group, and received no drug (Figure 1).

Women were recruited from St Mary's Hospital, Manchester and Tameside General Hospital between October 2012 and February 2014. All participants gave written, informed consent. Approvals were received from the North West Centre for Research Ethics Committee and the Medicines and Healthcare Products Regulatory Agency (MHRA). The study was prospectively registered on the European (EudraCT 2011-001382-40) and UK (ISRCTN 81570194) clinical trial databases.

Women taking metformin were monitored for toxicity by telephone call. Adverse events (AEs) were graded using Common Terminology Criteria for Adverse Events (CTCAE) v.3.0 (National Institute of Health, 2010). Where gastrointestinal side effects were intolerable, women withheld metformin until they subsided and recommenced at $850 \mathrm{mg}$ daily, followed by $850 \mathrm{mg}$ twice daily when tolerated. A final pill count established cumulative exposure

CONSORT diagram for the study indicating patient screening and accrual for the course of the study

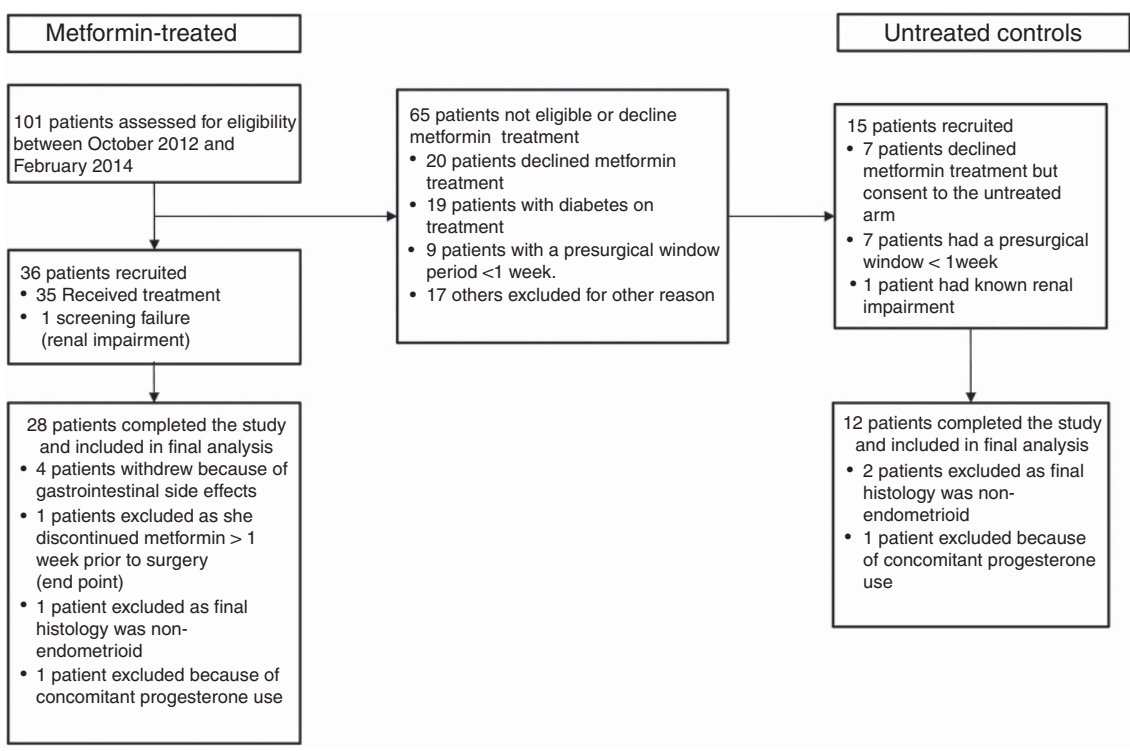

Figure 1. Flow chart showing study enrolment, withdrawals and exclusions. Concerns about starting a new drug with potential gastrointestinal side effects, inability to adhere to strict follow-up procedures and psychological distress at their recent cancer diagnosis were the most common reasons given for declining participation in the study. 
and treatment compliance. The cumulative dose was divided by days on treatment to calculate the average daily dose.

To assess the known effects of metformin on weight and markers of insulin resistance, at baseline and hysterectomy, height, weight and BMI; waist and hip circumference; and fasting blood glucose, insulin, C-peptide, adiponectin, leptin and high-sensitivity C-reactive protein (hsCRP) were measured. The homeostasis model of assessment of insulin resistance index (HOMA-IR) is the product of fasting glucose and insulin by 22.5 (Matthews et al, 1985). Tumour samples were taken at recruitment and at hysterectomy for histopathology and immunohistochemistry (IHC) analyses. A blind biopsy was taken at recruitment using a Pipelle endometrial sampling device; the final tumour sample was taken from the hysterectomy specimen, sampled and processed for clinical decision-making according to standard protocols. The diagnostic Pipelle was used as the baseline biopsy when hysterectomy was scheduled for $<7$ days' time or the recruitment biopsy was not obtained or insufficient for analysis. Consultant gynaecological histopathologists assessed all histopathology samples. Histological subtype, grade, stage, depth of myometrial invasion and the presence of lymphovascular space invasion were assessed using the FIGO 2009 Endometrial Cancer Staging System.

Immunohistochemical analysis. The primary end point was change in Ki-67 proliferation index. This was the percentage of tumour nuclei positively stained for $\mathrm{Ki}-67$ at hysterectomy compared with baseline. Automated IHC staining was performed on $4-\mu \mathrm{m}$ formalin-fixed paraffin-embedded sections using the Leica Bond Max (Leica Biosystems, Wetzlar, Germany) with heatinduced epitope retrieval. The primary antibody, Ki-67 MIB-1 clone (Dako, Carpinteria, CA, USA), was incubated for $60 \mathrm{~min}$ at a $1: 100$ dilution. Primary antibody detection was performed using the Refine Detection Kit (Leica Biosystems). The slides were counterstained with haematoxylin. Negative (isotype control) and positive (tonsil) controls were used for quality assurance.

Full slides were digitised using the Leica SCN400 Slide Scanner (Leica Microsystems, Wetzlar, Germany). To reduce bias and heterogeneity, RM selected equivalent areas to be scored on the pre- and postintervention sections using the haematoxylin and eosin slides. She was blinded to treatment group and intensity of staining for Ki-67 in the areas she selected. The Ki-67 proliferation index was determined from $>2000$ nuclei scored in $>3$ high powered fields $(\times 20)$. A semiautomated score was obtained by applying a computerised algorithm (Definiens Developer) to the malignant glands, which had been selected manually (Supplementary Figure S1). The Pipelle baseline sample was a scrape from the tumour surface while the hysterectomy specimen provided full tumour thickness. To reduce the bias inherent to comparing tumour from two different sampling methods, we restricted Ki-67 scoring to the luminal (surface) aspect of the tumour in the hysterectomy specimen. All scoring was performed by two independent scorers (VS, SK) who were blinded to treatment group. The interobserver intraclass correlation coefficient (ICC) was 0.97 (95\% CI 0.96, 0.98) and any discrepancies were reviewed together and resolved by consensus agreement.

Secondary end points included phosphorylated proteins from the PI3K-AKT-mTOR pathway and apoptotic markers. Tissue microarrays (TMAs) were created from triplicate cores of equivalent areas in pre- and postintervention biopsies selected by the study histopathologist (RM), who was blinded to treatment group. Automated IHC was performed using the Leica Bond Max (Leica Biosystems) with heat-induced epitope retrieval. The primary antibodies were: (1) phospho-AKT (p-AKT, Ser 473) at 1:50 dilution; (2) phospho-S6 (p-S6, Ser 235/236) at 1:400 dilution; (3) phospho-acetyl-CoA carboxylase (p-ACC, Ser 79) at 1:300 dilution; (4) phospho-4EBP1 (p-4EBP1, Thr 37/46) at 1:800 dilution; (5) PTEN Clone 6H2.1 (Dako) at 1:600 dilution; and (6) cleaved caspase-3 at 1:200 dilution. All antibodies were from Cell Signalling (Beverley, MA, USA), unless otherwise stated.

$\mathrm{p} 53$, oestrogen receptor (ER) and progesterone receptor (PR) status were analysed in the clinical histopathology laboratory according to standard protocols using the automated Ventana BenchMark XT (Ventana, Tucson, AZ, USA). The primary antibodies used were: (1) p53 Clone D07 (Leica Biosystems) at 1:50 dilution; (2) ER Clone SP1 (Roche, Basel, Switzerland); and PR Clone 1E2 (Roche). The same horseradish peroxidase-linked secondary antibody (Ventana) was used for all analyses; the chromagens were sequential $\mathrm{DAB}$ and copper. The slides were counterstained using haematoxylin and a bluing agent.

p-AKT, p-ACC, p-S6, p-4EBP1, ER and PR staining was assessed by modified $H$-score, the product of area score (proportion of positively stained core, scored 0-6) and intensity of staining score $(0=$ none, $1=$ mild, $2=$ moderate, $3=$ strong). $\mathrm{p}-\mathrm{AKT}, \mathrm{p}-\mathrm{ACC}$ and p-S6 staining was assessed in the cytoplasm and nucleus, whereas $\mathrm{p}-4 \mathrm{EBP} 1, \mathrm{ER}$ and PR were nuclear. PTEN was positive (strong staining of entire section) or negative $(<10 \%$ staining of malignant glands despite strong staining of adjacent stroma) (Garg et al, 2012). p53 was 'mutant-like' if $>50 \%$ of the tumour nuclei showed strong staining, when discrete geographical patterns showed strong staining, or when no p53 was found in the entire tumour (McCluggage et al, 2011; Nout et al, 2012). Cleaved caspase-3 (cc3) staining was scored by Definiens computerised algorithm that detected positive and negative nuclei and generated a cc3-positive index (percentage of cells positive for cc3). These were checked manually in view of the low proportion of cc3positive cells. All TMA scoring was completed by two independent scorers (VS, SK) who were blinded to time point and treatment group. The interobserver ICCs were all $>0.94$ and any discrepancies were reviewed together and resolved by consensus agreement.

Enzyme-linked immunosorbent assay. Fasting serum glucose, insulin and C-peptide were measured by automated assay according to routine clinical care standard operating procedures. Adiponectin and leptin were measured using a DuoSet ELISA Development Kit (R\&D Systems, Abingdon, UK). High-sensitivity CRP was measured by an in-house antibody sandwich ELISA technique with anti-human CRP primary antibodies, calibrators and controls from Abcam (Cambridge, UK). Intra-assay coefficients of variability $(\mathrm{CV})$ were $3 \%, 5 \%$ and $5 \%$ for adiponectin, leptin and hsCRP, respectively. Interassay CVs were $9 \%, 7 \%$ and $6 \%$, respectively.

Statistical analysis. The study was powered to observe a $20 \%$ reduction in Ki-67 following treatment. Assuming a median baseline Ki-67 proliferation index of $50 \%$, a standard deviation of $20 \%$ (in house unpublished data) and a correlation of $70 \%$ between pre- and postintervention measurements, a sample size of 29 would have $80 \%$ power to detect a $20 \%$ change in $\mathrm{Ki}-67$ at the $P=0.05$ significance level. We aimed to recruit 30 women to receive metformin, with opportunistic recruitment of as many contemporaneous controls as possible.

Treatment effect was analysed using an analysis of covariance linear regression model, with post-treatment score as the response variable, and baseline score, age, BMI, insulin resistance (HOMAIR) and treatment group as covariates. The effect of treatment on serum markers of insulin resistance used the same analysis of covariance, but excluded HOMA-IR as a covariate. Correlations were calculated using Spearman's rank-sum correlation coefficients. Descriptive statistics, including mean and s.d. for normally distributed data, and median and interquartile range (IQR), for nonparametric data, were used to compare the two groups of patients. 


\section{RESULTS}

Study population and baseline parameters. In total, 28 women received metformin and 12 received no drug in the presurgical window period between diagnosis and hysterectomy (Figure 1). Baseline demographics are shown in Table 1. The two groups were evenly matched in age (mean 64 vs 68 years) and BMI (mean 35 vs $32 \mathrm{~kg} \mathrm{~m}^{-2}$ ) in the treated and untreated groups, respectively). Eighty percent of all women were overweight or obese. Four had undiagnosed diabetes (fasting serum glucose $>7.0 \mathrm{mmoll}^{-1}$ ) and $60 \%$ were insulin resistant (fasting glucose $6.0-6.9 \mathrm{mmoll}^{-1}$ or HOMA-IR >2.8). Most women had low-grade, early-stage tumours (22 out of 28 of metformin-treated and 9 out of 12 untreated women, respectively).

Duration and tolerability of metformin treatment. Women received metformin for a median of 20 days (IQR 17, 24). Seventyfive percent of women experienced AEs but $96 \%$ of these were scored as grade 1 AEs (Table 2). Four patients withdrew from the study completely due to unacceptable gastrointestinal side effects. Thirteen others omitted one or more dose to reduce side effects. The median daily dose received was $1573 \mathrm{mg}$ (IQR 1475, 1659).

Effects of metformin on Ki-67 proliferation index. Baseline $\mathrm{Ki}$ 67 levels were similar in the two groups (mean 50.9\% (s.d. 17.1\%) in the metformin-treated vs $55.6 \%$ (s.d. $25.1 \%$ ) in the untreated women) (Table 3). Baseline Ki-67 was significantly associated with tumour grade (Spearman's correlation coefficient 0.37, 95\% CI $0.06,0.62, P=0.018$; Supplementary Figure S2). There was also a significant negative correlation between baseline Ki-67 expression and insulin resistance status (HOMA-IR) (Spearman's correlation coefficient $-0.43,95 \%$ CI $-0.66,-0.13, P=0.006$ ), but no relationship with BMI, age, stage or treatment group.

Ki-67 proliferation index was $17.2 \%$ lower following metformin treatment (adjusted mean difference - 17.2\% (95\% CI $-27.4 \%$, $-7.0 \%), P=0.002$ ) after adjustment for baseline Ki-67, age, BMI, insulin resistance (HOMA-IR) and change in the untreated women. Each line in Figure 2A represents the postintervention change in Ki-67 for an individual woman. A lower Ki-67 was observed in 23 out of 28 (82\%) women in the metformin group (range -4 to $-55 \%$ ); the remaining five $(18 \%)$ showed static or higher Ki-67 levels (range 0.6-14\%). There was some evidence of an association between the average metformin dose received and change in Ki-67 (Spearman's correlation coefficient $r=-0.37$, $95 \%$ CI $-0.66,0.01, P=0.051$; Supplementary Figure S3A). A nonsignificant correlation was also observed between baseline BMI and Ki-67 proliferation index change with metformin (Spearman's correlation coefficient $r=0.37,95 \%$ CI $-0.02,0.66$, $P=0.054$; Supplementary Figure S3B), with leaner women showing a greater Ki-67 change post-treatment with metformin than obese women. Five of $12(42 \%)$ untreated women showed modest reductions in Ki-67 between baseline and hysterectomy (range -1 to $-7 \%$ ), but Ki-67 remained static or increased in most (7 out of 12 women (58\%) showed a 1-28\% increase in Ki-67).

The interval between baseline and hysterectomy was similar for metformin-treated and -untreated women (median 30 days (IQR $22,43)$ vs 34 days (IQR 28, 39), respectively). The diagnostic biopsy was used as the baseline sample when a recruitment biopsy was not available. When postintervention change in Ki-67 was assessed using diagnostic biopsies as the baseline sample for all patients $(n=40)$, the reduction in Ki-67 in metformin-treated women remained significant (mean adjusted difference - 16\% (95\% CI $-27,-5 \%), P=0.005)$.

Effects of metformin on markers of obesity and insulin resistance. Short-term metformin was associated with improvements in serum markers of insulin resistance and adiposity (median change in fasting glucose $-0.3 \mathrm{mmoll}^{-1}$; insulin $-7.0 \mathrm{mUl}^{-1}$; HOMA-IR - 2.7; and leptin $-2.3 \mathrm{ng} \mathrm{ml}^{-1}$ ), but these were not statistically significant after adjusting for changes in the untreated group (Table 3).

Effects of metformin on phosphorylated mTOR proteins, markers of apoptosis and hormone receptor expression. There were global reductions in the expression of phosphorylated mTOR pathway proteins in both groups. Figure 3 shows phospho-AKT, phospho-ACC, phospho-S6 and phospho-4EBP1 expression in metformin-treated and -untreated patients at hysterectomy compared with baseline. p-4EBP1 expression was significantly lower in the metformin-treated patients compared with the untreated group (mean adjusted difference in modified $H$-score of -2.30 (95\% CI $-4.61,-0.06, P=0.045)$ ). The change in expression of the other phosphorylated mTOR pathway proteins was not statistically significant for treatment effect.

The baseline rate of apoptosis was very low (mean positive index 0.01 and 0.003 in metformin-treated and -untreated patients, respectively). We found no correlation between apoptotic index and grade of tumour, but there were very few grade 3 tumours $(n=4$ out of 40$)$. The apoptotic index remained stable over time in both groups; there was no significant effect of treatment (mean adjusted difference 0.00052 , 95\% CI $-0.0015,0.0025, P=0.608$, not significant). Oestrogen receptor and PR expression was lower in the hysterectomy specimen compared with the diagnostic biopsies of women from both groups. There was no significant effect of treatment.

\section{DISCUSSION}

This is the largest study of presurgical metformin treatment in EC conducted to date. A particular strength of the study is the untreated control group, as the variability of serum and tissue biomarkers between diagnosis and hysterectomy has not been studied before. Although not randomised, the two groups were evenly matched in terms of age, BMI, insulin resistance status, tumour grade and stage. We found that Ki-67 expression was stable on sequential biopsies taken before hysterectomy (data not shown) and a significant reduction in Ki-67 expression was only observed at the time of hysterectomy in the metformin-treatment group. By contrast, a reduction in the expression of phosphorylated PI3K-AKT-mTOR pathway proteins was observed at hysterectomy in both the metformin-treated and -untreated women. Hysterectomy specimens were bisected and immersed in formalin within $30 \mathrm{~min}$ of resection. This fixation protocol is standard for routine clinical care and achieves adequate preservation of tissue architecture and the expression of stable proteins like Ki-67, but unstable phosphorylation events may be lost. Future studies should consider taking a blinded biopsy at hysterectomy before devascularisation of the uterus; this would allow preservation of unstable phosphorylation events and facilitate the comparison of tumour biomarkers pre/postintervention on sequential biopsies achieved using the same sampling method.

Most of our patients were overweight or obese and the prevalence of undiagnosed T2DM and insulin resistance was striking. These observations are consistent with previous work (Burzawa et al, 2011; Crosbie et al, 2012). Cancer clinicians should have heightened awareness that diabetes (known and undiagnosed) is common amongst women with EC. We observed changes in biomarkers of insulin resistance and adiposity between baseline and hysterectomy in both groups. Whilst weight loss and its associated impact on insulin resistance is a recognised consequence of advanced stage cancer (Fearon et al, 2011), the majority of our patients had good prognosis tumours diagnosed at an early stage. The mediator of these alterations may therefore be anxiety-induced 
Table 1. Baseline patient and tumour characteristics at recruitment.

\begin{tabular}{|c|c|c|c|c|c|c|c|}
\hline Baseline parameters & $\begin{array}{l}\text { Metformin } \\
\text { Mean } \\
\text { Median }\end{array}$ & $\begin{array}{l}28 \\
\text { S.d. } \\
\text { Q1 }\end{array}$ & Q3 & $\begin{array}{l}\text { Control } \\
\text { Mean } \\
\text { Median }\end{array}$ & $\begin{array}{l}12 \\
\text { S.d. } \\
\text { Q1 }\end{array}$ & Q3 & $P$-value ${ }^{\text {a }}$ \\
\hline Age (years) & $\begin{array}{l}63.6 \\
63.5\end{array}$ & $\begin{array}{r}8.9 \\
58.0\end{array}$ & 69.5 & $\begin{array}{l}67.8 \\
70.0\end{array}$ & $\begin{array}{l}9.2 \\
63.5\end{array}$ & 70.5 & 0.17 \\
\hline $\begin{array}{l}<50 \\
51-60 \\
61-70 \\
71-80 \\
>80\end{array}$ & $\begin{array}{c}1 \\
10 \\
11 \\
5 \\
1\end{array}$ & $\begin{array}{r}3.6 \% \\
35.7 \% \\
39.3 \% \\
17.9 \% \\
3.6 \% \\
\end{array}$ & & $\begin{array}{l}0 \\
2 \\
7 \\
2 \\
1\end{array}$ & $\begin{array}{c}0.0 \% \\
16.7 \% \\
58.3 \% \\
16.7 \% \\
8.3 \%\end{array}$ & & \\
\hline Body mass index $\left(\mathrm{kg} \mathrm{m}^{-2}\right)$ & $\begin{array}{l}35.5 \\
34.1\end{array}$ & $\begin{array}{l}11.3 \\
26.8\end{array}$ & 42.9 & $\begin{array}{l}32.0 \\
33.2\end{array}$ & $\begin{array}{l}5.9 \\
27.0\end{array}$ & 34.8 & 0.52 \\
\hline $\begin{array}{l}<25 \\
25-29.9 \\
>30-39.9 \\
>40\end{array}$ & $\begin{array}{l}6 \\
5 \\
8 \\
9\end{array}$ & $\begin{array}{l}21.4 \% \\
17.9 \% \\
28.6 \% \\
32.1 \%\end{array}$ & & $\begin{array}{l}2 \\
3 \\
5 \\
2\end{array}$ & $\begin{array}{l}16.7 \% \\
25.0 \% \\
41.7 \% \\
16.7 \%\end{array}$ & & \\
\hline HOMA-IR index & $\begin{array}{l}4.36 \\
3.96\end{array}$ & $\begin{array}{l}2.75 \\
2.07\end{array}$ & 5.75 & $\begin{array}{l}3.24 \\
2.25\end{array}$ & $\begin{array}{l}2.34 \\
1.43\end{array}$ & 4.32 & 0.12 \\
\hline Insulin resistance (HOMA-IR > 2.8) & 17 & $60.7 \%$ & & 5 & $41.7 \%$ & & \\
\hline \multicolumn{8}{|l|}{ Tumour grade at hysterectomy } \\
\hline $\begin{array}{l}\mathrm{AEH} \\
\mathrm{G} 1 \\
\mathrm{G} 2 \\
\mathrm{G} 3\end{array}$ & $\begin{array}{c}0 \\
14 \\
13 \\
1\end{array}$ & $\begin{array}{r}0.0 \% \\
50.0 \% \\
46.4 \% \\
3.6 \%\end{array}$ & & $\begin{array}{l}2 \\
1 \\
6 \\
3\end{array}$ & $\begin{array}{c}16.7 \% \\
8.3 \% \\
50.0 \% \\
25.0 \%\end{array}$ & & \\
\hline \multicolumn{8}{|l|}{ Myometrial invasion ${ }^{\mathbf{b}}$} \\
\hline $\begin{array}{l}<50 \% \\
\geqslant 50 \%\end{array}$ & $\begin{array}{c}22 \\
6\end{array}$ & $\begin{array}{l}78.6 \% \\
21.4 \%\end{array}$ & & $\begin{array}{l}7 \\
3\end{array}$ & $\begin{array}{l}58.3 \% \\
25.0 \%\end{array}$ & & \\
\hline \multicolumn{8}{|l|}{ Follow-up and adjuvant therapy ${ }^{b}$} \\
\hline $\begin{array}{l}\text { Clinical follow-up }{ }^{c} \\
\text { Vaginal brachytherapy } \\
\text { External beam radiotherapy } \\
\text { External beam radiotherapy and chemotherapy } \\
\text { Chemotherapy alone }\end{array}$ & $\begin{array}{l}17 \\
3 \\
2 \\
3 \\
3\end{array}$ & $\begin{array}{r}60.7 \% \\
10.7 \% \\
7.1 \% \\
10.7 \% \\
3.6 \%\end{array}$ & & $\begin{array}{l}6 \\
2 \\
1 \\
1 \\
0\end{array}$ & $\begin{array}{c}60.0 \% \\
20.0 \% \\
10.0 \% \\
10.0 \% \\
0.0 \%\end{array}$ & & \\
\hline \multicolumn{8}{|l|}{ ER expression } \\
\hline $\begin{array}{l}\text { Positive } \\
\text { Negative }\end{array}$ & $\begin{array}{c}28 \\
0\end{array}$ & $\begin{array}{r}100.0 \% \\
0.0 \%\end{array}$ & & $\begin{array}{r}11 \\
1\end{array}$ & $\begin{array}{l}91.7 \% \\
8.3 \%\end{array}$ & & \\
\hline \multicolumn{8}{|l|}{ PR expression } \\
\hline $\begin{array}{l}\text { Positive } \\
\text { Negative }\end{array}$ & $\begin{array}{c}28 \\
0\end{array}$ & $\begin{array}{r}100.0 \% \\
0.0 \%\end{array}$ & & $\begin{array}{r}12 \\
0\end{array}$ & $\begin{array}{c}100.0 \% \\
0.0 \%\end{array}$ & & \\
\hline \multicolumn{8}{|l|}{ PTEN expression } \\
\hline $\begin{array}{l}\text { Wild type } \\
\text { Mutant }\end{array}$ & $\begin{array}{c}19 \\
9\end{array}$ & $\begin{array}{l}67.9 \% \\
32.1 \%\end{array}$ & & $\begin{array}{l}9 \\
3\end{array}$ & $\begin{array}{l}75.0 \% \\
25.0 \%\end{array}$ & & \\
\hline \multicolumn{8}{|l|}{ P53 expression } \\
\hline $\begin{array}{l}\text { Wild type } \\
\text { Mutant }\end{array}$ & $\begin{array}{c}27 \\
1\end{array}$ & $\begin{array}{r}96.4 \% \\
3.6 \%\end{array}$ & & $\begin{array}{r}11 \\
1\end{array}$ & $\begin{array}{l}91.7 \% \\
8.3 \%\end{array}$ & & \\
\hline \multicolumn{8}{|c|}{ 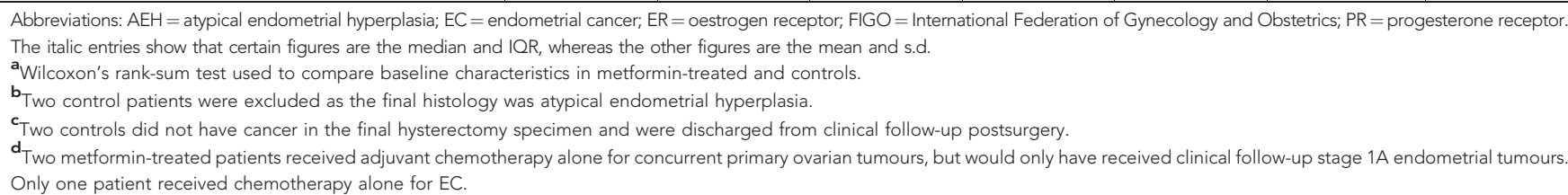 } \\
\hline
\end{tabular}


behavioural change or intentional weight loss in preparation for surgery. Previous window studies in EC (Laskov et al, 2014) and breast cancer (Niraula et al, 2012) reported significant changes in biomarkers of adiposity and insulin resistance after short-term metformin treatment, but the lack of a control group hinders interpretation of these data. A large randomised window study in

Table 2. AEs experienced by all patients who participated in the metformin-treatment group

\begin{tabular}{|l|r|r|}
\hline $\begin{array}{l}\text { Summary of AEs experienced by all patients } \\
\text { who received metformin treatment }\end{array}$ & $\mathbf{n}$ & (\%) \\
\hline Patients who received at least one dose of metformin & 35 & 100 \\
\hline Patients who developed any AEs & 27 & 77 \\
\hline Number of AEs & 98 & 100 \\
Grade 1 AE & 94 & 96 \\
Grade 2 AE & 3 & 3 \\
Grade 3 AE & 1 & 1 \\
\hline
\end{tabular}

\section{No. of patients experiencing an $\mathrm{AE}$}

\begin{tabular}{|l|r|c|}
\hline Loss of appetite & 4 & 11 \\
Nausea/vomiting & 27 & 77 \\
Diarrhoea & 24 & 69 \\
Abdominal pain & 12 & 34 \\
Skin changes & 3 & 9 \\
Headache & 3 & 9 \\
Fatigue & 2 & 6 \\
Bloating & 2 & 6 \\
Abnormal baseline bloods & 10 & 29 \\
Others & 11 & 31 \\
\hline Mean patient tolerability scores $(0=$ not tolerable, & 29 & 6.1 (s.d. 2.5) \\
10=very tolerable) & & \\
\hline Abbreviation: AE =adverse events. &
\end{tabular}

Abbreviation: $\mathrm{AE}=$ adverse events. breast cancer that adjusted for changes in untreated controls found no effect of metformin on BMI or insulin resistance after four weeks of treatment (DeCensi et al, 2014). The latter study had a lower prevalence of overweight/obesity (40\%) and insulin resistance $(27 \%)$ compared with that we report here. Other studies have demonstrated a beneficial impact of metformin on BMI and markers of insulin resistance after a full six months' of treatment in breast cancer patients (Goodwin et al, 2015) as well as euglycaemic obese healthy women (Worsley et al, 2014), suggesting that the lack of demonstrable effect of metformin on biomarkers of adiposity and insulin resistance reflects the short duration of treatment in this study.

Metformin was generally well tolerated, although 4 out of 36 patients withdrew from the study due to gastrointestinal side effects. When treating T2DM, it is standard to commence metformin at a low dose and build up gradually to limit gastrointestinal toxicity. In this study, metformin was commenced at full dose to maximise the total amount of metformin received before hysterectomy. It is not known whether standard diabetic doses of metformin are sufficient for anticancer activity in vivo. In preclinical laboratory studies, supradiabetic concentrations of metformin are required to achieve a growth static effect using cancer cell lines (Cantrell et al, 2010; Sarfstein et al, 2013; Lengyel et al, 2015). Mitsuhashi et al (2014) found metformin at concentrations of $1.2-5.1 \mu \mathrm{mol} \mathrm{kg}^{-1}$ in EC, equivalent to $\sim 20 \%$ of circulating serum levels. The effective concentration of metformin in EC is therefore 1/400 lower compared with concentrations required to suppress proliferation in vitro. Optimal anticancer doses of metformin to be used in clinical studies have yet to be established. No studies have performed a dose-escalation protocol and previous window studies have given typical diabetic

Table 3. Change from baseline following intervention

\begin{tabular}{|c|c|c|c|c|c|c|c|c|c|c|c|c|c|}
\hline \multirow[b]{3}{*}{$\begin{array}{l}\text { Tumour and } \\
\text { metabolic } \\
\text { parameters }\end{array}$} & \multirow[b]{3}{*}{ Unit } & \multicolumn{4}{|c|}{ Metformin } & \multicolumn{4}{|c|}{ Untreated } & & & & \\
\hline & & \multirow{2}{*}{\begin{tabular}{|c|} 
Mean \\
Median
\end{tabular}} & (S.d.) & \multirow{2}{*}{\begin{tabular}{c|} 
Mean \\
Median
\end{tabular}} & (S.d.) & \multirow{2}{*}{\begin{tabular}{|c|} 
Mean \\
Median \\
\end{tabular}} & (S.d.) & \multirow{2}{*}{$\begin{array}{c}\text { Mean } \\
\text { Median }\end{array}$} & (S.d.) & & \multicolumn{2}{|c|}{$95 \% \mathrm{Cl}$} & \\
\hline & & & Q1 Q3 & & Q1 Q3 & & Q1 Q3 & & Q1 $\mathrm{Q3}$ & $\begin{array}{l}\text { Adjusted } \\
\text { mean } \\
\text { difference }\end{array}$ & Upper & Lower & $P$-value \\
\hline Body mass index & $\mathrm{kg} \mathrm{m}^{-2}$ & 35.5 & $\frac{1}{(11.3)}$ & 35.1 & $\frac{1}{(10.9)}$ & 32.0 & (5.9) & 31.9 & (6.0) & -0.1 & -0.6 & 0.3 & 0.53 \\
\hline & & 34.1 & \begin{tabular}{l|l}
26.8 & 42.9 \\
\end{tabular} & 34.4 & \begin{tabular}{l|l}
26.4 & 41.9
\end{tabular} & 33.2 & \begin{tabular}{l|l}
27.0 & 34.8 \\
\end{tabular} & 32.6 & \begin{tabular}{|l|l|}
27.1 & 35.2 \\
\end{tabular} & & & & \\
\hline Waist/hip girth ratio & & 0.9 & $(0.1)$ & 0.9 & $(0.1)$ & 0.9 & $(0.1)$ & 0.9 & $(0.1)$ & 0.0 & 0.0 & 0.0 & 0.97 \\
\hline & & 0.9 & \begin{tabular}{l|l}
0.8 & 0.9
\end{tabular} & 0.9 & \begin{tabular}{l|l}
0.8 & 0.9
\end{tabular} & 0.9 & \begin{tabular}{l|l}
0.8 & 0.9
\end{tabular} & 0.9 & \begin{tabular}{l|l}
0.8 & 0.9 \\
\end{tabular} & & & & \\
\hline Glucose & $\mathrm{mmoll}^{-1}$ & 6.0 & $(1.5)$ & 5.5 & (1.3) & 5.7 & $(0.7)$ & 5.3 & $(0.6)$ & 0.2 & -0.4 & 0.7 & 0.56 \\
\hline & & 5.6 & \begin{tabular}{l|l}
5.0 & 6.4 \\
\end{tabular} & 5.3 & \begin{tabular}{l|l}
4.9 & 5.9 \\
\end{tabular} & 5.6 & \begin{tabular}{l|l}
5.2 & 6.3 \\
\end{tabular} & 5.3 & \begin{tabular}{|l|l|}
5.1 & 5.6
\end{tabular} & & & & \\
\hline C-peptide & $\mathrm{pmoll}^{-1}$ & 1076.1 & $(482.3)$ & 985.4 & $(525.3)$ & 896.4 & $(341.0)$ & 781.0 & $(461.2)$ & 44.7 & -206.2 & 295.5 & 0.72 \\
\hline & & 1055.0 & \begin{tabular}{|l|l|}
655.0 & 1365.0 \\
\end{tabular} & 1000.0 & \begin{tabular}{|l|l|}
560.0 & 1295.0 \\
\end{tabular} & 860.0 & \begin{tabular}{|l|l|}
605.0 & 1023.5
\end{tabular} & 750.0 & \begin{tabular}{|l|l|}
600.0 & 985.0 \\
\end{tabular} & & & & \\
\hline Adiponectin & $\mathrm{mgl}^{-1}$ & 3.3 & (1.5) & 2.8 & (1.1) & 3.4 & $(1.3)$ & 3.1 & $(1.2)$ & -0.3 & -0.7 & 0.2 & 0.21 \\
\hline & & 2.6 & \begin{tabular}{l|l}
2.3 & 4.6
\end{tabular} & 2.5 & \begin{tabular}{l|l}
1.9 & 3.6 \\
\end{tabular} & 3.1 & \begin{tabular}{l|l}
2.3 & 4.2 \\
\end{tabular} & 2.6 & \begin{tabular}{|l|l|}
2.3 & 4.1 \\
\end{tabular} & & & & \\
\hline Leptin & $\mathrm{ngml}^{-1}$ & 54.1 & $(42.6)$ & 57.9 & $(46.7)$ & 42.9 & $(23.0)$ & 45.5 & $(23.5)$ & -2.1 & -13.2 & 9.0 & 0.70 \\
\hline & & 55.0 & \begin{tabular}{l|l}
19.3 & 82.5 \\
\end{tabular} & 52.7 & \begin{tabular}{l|l}
20.2 & 84.1
\end{tabular} & 42.8 & \begin{tabular}{l|l}
21.5 & 63.9
\end{tabular} & 43.8 & \begin{tabular}{|l|l|}
27.6 & 63.8 \\
\end{tabular} & & & & \\
\hline Ln (hsCRP) & $\mathrm{mgl}^{-1}$ & 1.3 & $(1.3)$ & 0.8 & $(1.4)$ & 0.9 & $(1.1)$ & 0.6 & $(1.2)$ & 0.0 & -0.8 & 0.8 & 0.99 \\
\hline & & 1.3 & \begin{tabular}{l|l|}
0.2 & 1.9 \\
\end{tabular} & 1.0 & \begin{tabular}{l|l}
0.2 & 1.5 \\
\end{tabular} & 1.2 & \begin{tabular}{l|l}
-0.2 & 1.7 \\
\end{tabular} & 1.0 & \begin{tabular}{|l|l|}
-0.5 & 1.4 \\
\end{tabular} & & & & \\
\hline $\begin{array}{l}\text { Abbreviations: ANCC } \\
\text { protein. The treatmer } \\
\text { insulin resistance }(\mathrm{HO} \\
\text { are the median and I }\end{array}$ & $=$ analysis & of covaria & nce; BMI, body r & mass index; & $; \mathrm{Cl}=$ confiden & e interval; t & $\mathrm{HOMA}-\mathrm{IR}=\mathrm{hom}$ & stasis mo & del of insulin & ance; hs & high-se & sitivity C. & $\begin{array}{l}\text { reactive } \\
\text { ge, BMI, } \\
\text { figures }\end{array}$ \\
\hline
\end{tabular}


doses of 500-2250 mg metformin per day (Laskov et al, 2014; Mitsuhashi et al, 2014; Schuler et al, 2015). In this study, we observed a Ki-67 drop associated with metformin treatment and this was positively correlated with the average daily dose of metformin received. It is interesting to speculate whether higher doses would have had even greater impact. Metformin is not bound to plasma

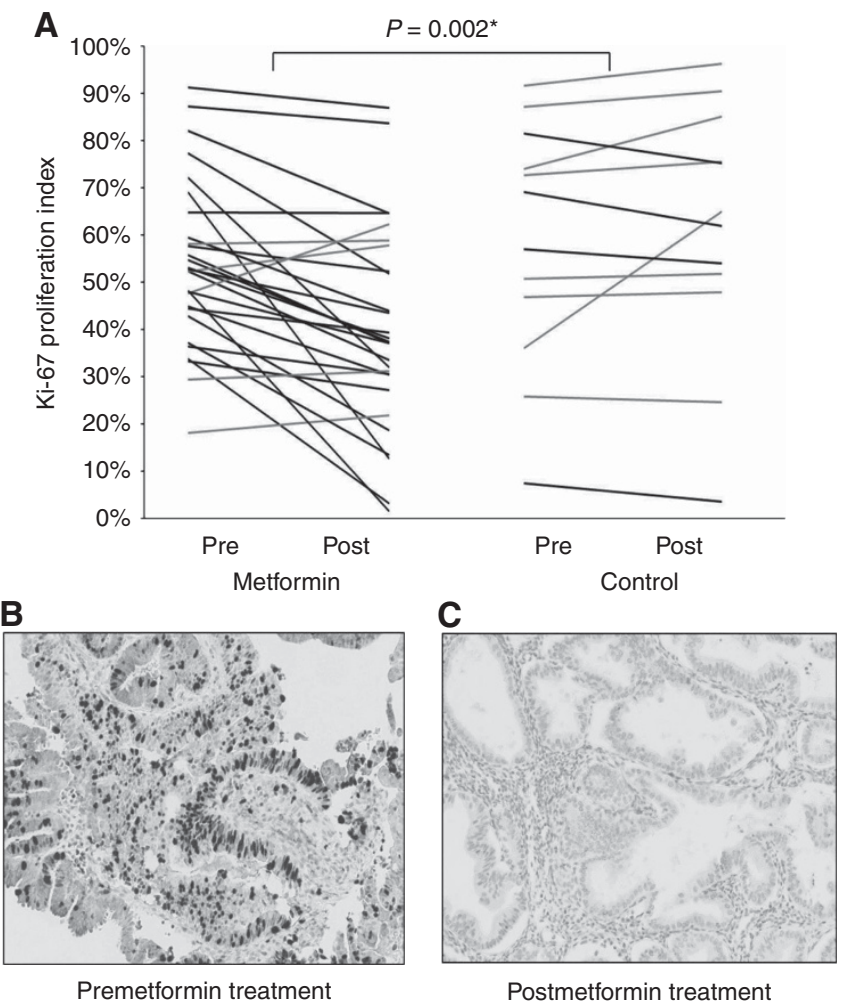

Figure 2. (A) Line graph showing the adjusted mean difference in Ki-67 proliferation index in paired pre- and postintervention endometrial tumours from metformin-treated and control patients. (B and $\mathbf{C}$ ) Endometrial tumour stained for Ki-67 before (B) and after (C) treatment with metformin at $\times 20$ magnification.
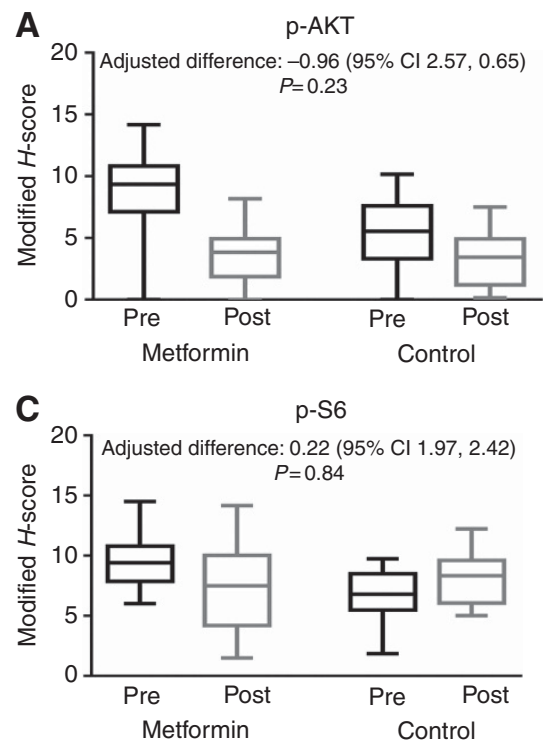

proteins (Tucker et al, 1981) and has a very high volume of distribution. The effective circulating dose of metformin may therefore vary with BMI. We found some evidence of this, with greater reductions in post-metformin Ki-67 observed in leaner patients. Based on these data, we hypothesise that higher doses of metformin may achieve superior anticancer effects, particularly in obese and morbidly obese women. There is considerable interindividual variation in glycaemic response to metformin in T2DM, partly explained by genetic differences in organic cation transporter1 (OCT-1) expression levels in hepatic and skeletal tissue (Graham et al, 2011; Berstein et al, 2013). No studies have measured OCT-1 expression levels in EC, but differences in levels may explain why some patients responded to metformin but others did not. Metformin accumulates in endometrial tissue but has a half-life of $6 \mathrm{~h}$; it is not known whether the timing of the last dose of metformin before serum and endometrial sampling affected our results.

The baseline level of apoptosis was very low in this study and there was no correlation with tumour grade. Apoptosis is poorly documented in EC; however, a similar window study investigating the effects of medroxyprogesterone acetate reported comparable low baseline values (Zaino et al, 2014). We also found no evidence for a proapoptotic effect of metformin in EC. In preclinical studies using EC cell lines, apoptosis is only induced at much higher concentrations of metformin compared with those required to inhibit cell growth (Cantrell et al, 2010).

$\mathrm{Ki}-67$ is an established prognostic and predictive biomarker in breast cancer (Dowsett et al, 2005, 2006, 2007), but there is little evidence for its use as a surrogate marker in EC. We and others have shown that high-grade tumours have higher Ki-67 levels; tumour grade is an established independent prognostic biomarker in EC. Several studies have found an association between high $\mathrm{Ki}-67$, other biomarkers of poor prognosis in EC and EC-specific mortality (Salvesen et al, 1998, 1999; Stefansson et al, 2004; Liu et al, 2014), but there is little consensus regarding optimal staining and scoring protocols to generate robust and reproducible data. We have adapted the International guidelines for Ki-67 staining and scoring in breast cancer established by Dowsett et al (2011) for this study. We developed a protocol for semiautomated scoring that is both reproducible and demonstrates excellent agreement with manual scoring. In breast cancer, a significant Ki-67 drop following short-term treatment with neoadjuvant chemotherapy is
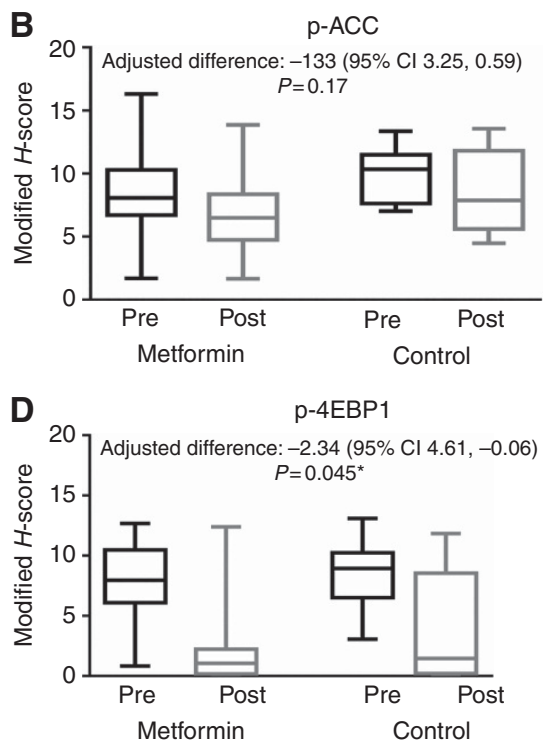

Figure 3. Phosphorylation changes in (A) AKT, (B) ACC, (C) S6 and (D) 4EBP1 using box and whisker plots representing the median modified $\mathrm{H}$-score (middle line) and the first and third quartile from paired pre- and postintervention endometrial biopsies for metformin-treated and control patients. The whiskers represent the maximum and minimum values. 
predictive of tumour responsiveness to that drug (Dowsett et al, $2005,2006,2007)$. Thus, presurgical window studies have been an efficient way of screening novel therapeutic strategies for breast cancer. This trial design also has great potential in EC, as a trial powered to assess the impact of a new drug in the adjuvant setting using recurrence or EC-specific survival as the end point would be extremely expensive to conduct, requiring thousands of participants over many years of follow-up. Furthermore, like the breast, the endometrium lends itself to sampling in the outpatient setting, facilitating the comparison of matched biopsies taken before and after intervention in the presurgical window period.

Our data add to the growing body of evidence supporting biological activity of metformin in EC that may have therapeutic potential. This is an exciting area of research that is likely to produce further evidence over the next few years. feMMe, a phase II randomised clinical trial, is assessing the additional benefit of metformin or weight loss in combination with the levonorgestrelreleasing intrauterine device in non-surgical patients with $\mathrm{AEH}$ and early EC (Hawkes et al, 2014). Another study is assessing the impact of metformin with paclitaxel and carboplatin for advanced stage or recurrent EC. In addition to its therapeutic role, it is interesting to speculate whether metformin could be used for primary prevention of EC in high-risk groups. Reducing insulin resistance, promoting modest weight loss or preventing further weight gain would seem plausible strategies for EC risk reduction in morbidly obese women. A study assessing the impact of short-term treatment with metformin or placebo with or without a lifestyle intervention program designed to achieve weight loss and increase activity levels is underway, using endometrial Ki-67 as the primary end point. The data from these and similar studies are eagerly awaited.

\section{CONCLUSION}

Short-term presurgical metformin treatment is associated with a significant drop in Ki-67 expression in EC. Changes in phosphorylated mTOR proteins and serum markers of insulin resistance are observed to some extent in both groups, emphasising the need for a control group to adjust for the variability of biomarkers over time. Indeed, the phosphorylation status of mTOR proteins in EC at hysterectomy may be more indicative of devascularisation of the uterus than study interventions. Future studies based on tissue end points should compare pre- and postintervention endometrial biopsies taken using the same sampling method and before devascularisation of the uterus.

\section{DISCLAIMER}

This article presents independent research funded by the National Institute for Health Research (NIHR). The views expressed are those of the authors and not necessarily those of the NHS, the NIHR or the Department of Health.

\section{ACKNOWLEDGEMENTS}

We thank all the women who participated in this study. We also thank Mrs Christina Pritchard, Mrs Linsey Nelson and all clinical staff at the participating hospitals for their support in the conduct of the clinical trial. VS is funded through a Wellcome Trust/ Wellbeing of Women Research Training Fellowship; SK is an NIHR Research Training Fellow; EC is an NIHR Clinician Scientist. This study was additionally funded through a Central Manchester University Hospitals NHS Foundation Trust Experimental Medicine Scheme.

\section{CONFLICT OF INTEREST}

The authors declare no conflict of interest.

\section{REFERENCES}

Arnold M, Pandeya N, Byrnes G, Renehan AG, Stevens GA, Ezzati M, Ferlay J, Miranda JJ, Romieu I, Dikshit R, Forman D, Soerjomataram I (2015) Global burden of cancer attributable to high body-mass index in 2012: a population-based study. Lancet Oncol 16: 36-46.

Berstein LM, Iyevleva AG, Vasilyev D, Poroshina TE, Imyanitov EN (2013) Genetic polymorphisms potentially associated with response to metformin in postmenopausal diabetics suffering and not suffering with cancer. Cell Cycle 12: 3681-3688.

Bonanni B, Puntoni M, Cazzaniga M, Pruneri G, Serrano D, Guerrieri-Gonzaga A, Gennari A, Trabacca M, Galimberti V, Veronesi P, Johansson H, Aristarco V, Bassi F, Luini A, Lazzeroni M, Varricchio C, Viale G, Bruzzi P, DeCensi A (2012) Dual effect of metformin on breast cancer proliferation in a randomized presurgical trial. J Clin Oncol 30: 2593-2600.

Burzawa J, Schmeler K, Soliman P, Meyer L, Bevers M, Pustilnik T, Anderson M, Ramondetta L, Tortolero-Luna G, Urbauer D, Chang S, Gershenson D, Brown J, Lu K (2011) Prospective evaluation of insulin resistance among endometrial cancer patients. Am J Obstet Gynecol 204: e1-e7.

Cantrell LA, Zhou C, Mendivil A, Malloy KM, Gehrig PA, Bae-Jump VL (2010) Metformin is a potent inhibitor of endometrial cancer cell proliferation-implications for a novel treatment strategy. Gynecol Oncol 116: $92-98$

Crosbie E, Zwahlen M, Kitchener H, Egger M, Renehan A (2010) Body mass index, hormone replacement therapy, and endometrial cancer risk: a meta-analysis. Cancer Epidemiol Biomarkers Prev 19: 3119-3130.

Crosbie EJ, Roberts C, Qian W, Swart AM, Kitchener HC, Renehan AG (2012) Body mass index does not influence post-treatment survival in early stage endometrial cancer: results from the MRC ASTEC trial. Eur J Cancer 48 : 853-864.

Cancer Research UK (2014) Uterine (womb) cancer incidence statistics [Online], London. Available at http://www.cancerresearchuk.org/cancerinfo/cancerstats/types/uterus/incidence/ (last accessed 5 May 2015).

DeCensi A, Puntoni M, Gandini S, Guerrieri-Gonzaga A, Johansson HA, Cazzaniga M, Pruneri G, Serrano D, Schwab M, Hofmann U, Mora S, Aristarco V, Macis D, Bassi F, Luini A, Lazzeroni M, Bonanni B, Pollak MN (2014) Differential effects of metformin on breast cancer proliferation according to markers of insulin resistance and tumor subtype in a randomized presurgical trial. Breast Cancer Res Treat 148: 81-90.

Dowsett M, Nielsen T, A'hern R, Bartlett J, Coombes R, Cuzick J, Ellis M, Henry L, Hugh J, Lively T, Mcshane L, Paik S, Penault-Llorca F, Prudkin L, Regan M, Salter J, Sotiriou C, Smith I, Viale G, Zujewski J, Hayes D (2011) Assessment of Ki67 in Breast Cancer: Recommendations from the International Ki67 in Breast Cancer Working Group. J Natl Cancer Inst 103: 1656-1664.

Dowsett M, Smith I, Ebbs S, Dixon J, Skene A, Griffith C, Boeddinghaus I, Salter J, Detre S, Hills M, Ashley S, Francis S, Walsh G, Trialists I (2005) Short-term changes in Ki-67 during neoadjuvant treatment of primary breast cancer with anastrozole or tamoxifen alone or combined correlate with recurrence-free survival. Clin Cancer Res 11: 915s-918ss.

Dowsett M, Smith IE, Ebbs SR, Dixon JM, Skene A, A'hern R, Salter J, Detre S, Hills M, Walsh G (2007) Prognostic value of Ki67 expression after short-term presurgical endocrine therapy for primary breast cancer. J Natl Cancer Inst 99: 167-170.

Dowsett M, Smith IE, Ebbs SR, Dixon JM, Skene A, Griffith C, Boeddinghaus I, Salter J, Detre S, Hills M, Ashley S, Francis S, Walsh G, A'hern R (2006) Proliferation and apoptosis as markers of benefit in neoadjuvant endocrine therapy of breast cancer. Clin Cancer Res 12: 1024s-1030s.

Evans J, Donnelly L, Emslie-Smith A, Alessi D, Morris A (2005) Metformin and reduced risk of cancer in diabetic patients. BMJ 330: 1304-1305.

Fearon K, Strasser F, Anker SD, Bosaeus I, Bruera E, Fainsinger RL, Jatoi A, Loprinzi C, Macdonald N, Mantovani G, Davis M, Muscaritoli M, Ottery F, Radbruch L, Ravasco P, Walsh D, Wilcock A, Kaasa S, Baracos VE (2011) Definition and classification of cancer cachexia: an international consensus. Lancet Oncol 12: 489-495. 
Friberg E, Orsini N, Mantzoros C, Wolk A (2007) Diabetes mellitus and risk of endometrial cancer: a meta-analysis. Diabetologia 50: 1365-1374.

Garg K, Broaddus RR, Soslow RA, Urbauer DL, Levine DA, Djordjevic B (2012) Pathologic scoring of PTEN immunohistochemistry in endometrial carcinoma is highly reproducible. Int J Gynecol Pathol 31: 48-56.

Goodwin PJ, Parulekar WR, Gelmon KA, Shepherd LE, Ligibel JA, Hershman DL, Rastogi P, Mayer IA, Hobday TJ, Lemieux J, Thompson AM, Pritchard KI, Whelan TJ, Mukherjee SD, Chalchal HI, Oja CD, Tonkin KS, Bernstein V, Chen BE, Stambolic V (2015) Effect of metformin vs placebo on and metabolic factors in NCIC CTG MA.32. J Natl Cancer Inst 107(3): djv006.

Graham GG, Punt J, Arora M, Day RO, Doogue MP, Duong JK, Furlong TJ, Greenfield JR, Greenup LC, Kirkpatrick CM, Ray JE, Timmins P, Williams KM (2011) Clinical pharmacokinetics of metformin. Clin Pharmacokinet 50: 81-98.

Hadad S, Iwamoto T, Jordan L, Purdie C, Bray S, Baker L, Jellema G, Deharo S, Hardie D, Pusztai L, Moulder-Thomson S, Dewar J, Thompson A (2011) Evidence for biological effects of metformin in operable breast cancer: a pre-operative, window-of-opportunity, randomized trial. Breast Cancer Res Treat 128: 783-794.

Hawkes AL, Quinn M, Gebski V, Armes J, Brennan D, Janda M, Obermair A (2014) Improving treatment for obese women with early stage cancer of the uterus: rationale and design of the levonorgestrel intrauterine device $+/$ - metformin $+/$ - weight loss in endometrial cancer (feMME) trial. Contemp Clin Trials 39: 14-21.

Joshua AM, Zannella VE, Downes MR, Bowes B, Hersey K, Koritzinsky M, Schwab M, Hofmann U, Evans A, Van Der Kwast T, Trachtenberg J, Finelli A, Fleshner N, Sweet J, Pollak M (2014) A pilot 'window of opportunity' neoadjuvant study of metformin in localised prostate cancer. Prostate Cancer Prostatic Dis 17: 252-258.

Laskov I, Drudi L, Beauchamp MC, Yasmeen A, Ferenczy A, Pollak M, Gotlieb WH (2014) Anti-diabetic doses of metformin decrease proliferation markers in tumors of patients with endometrial cancer. Gynecol Oncol 134: 607-614.

Lengyel E, Litchfield LM, Mitra AK, Nieman KM, Mukherjee A, Zhang Y, Johnson A, Bradaric M, Lee W, Romero IL (2015) Metformin inhibits ovarian cancer growth and increases sensitivity to paclitaxel in mouse models. Am J Obstet Gynecol 212: 479 e1-479 e10.

Libby G, Donnelly LA, Donnan PT, Alessi DR, Morris AD, Evans JM (2009) New users of metformin are at low risk of incident cancer: a cohort study among people with type 2 diabetes. Diabetes Care 32: 1620-1625.

Liu T, Gao H, Yang M, Zhao T, Liu Y, Lou G (2014) Correlation of TNFAIP8 overexpression with the proliferation, metastasis, and disease-free survival in endometrial cancer. Tumour Biol 35: 5805-5814.

Matthews D, Hosker J, Rudenski A, Naylor B, Treacher D, Turner R (1985) Homeostasis model assessment: insulin resistance and beta-cell function from fasting plasma glucose and insulin concentrations in man. Diabetologia 28: 412-419.

McCluggage WG, Soslow RA, Gilks CB (2011) Patterns of p53 immunoreactivity in endometrial carcinomas: 'all or nothing' staining is of importance. Histopathology 59: 786-788.

Mitsuhashi A, Kiyokawa T, Sato Y, Shozu M (2014) Effects of metformin on endometrial cancer cell growth in vivo: a preoperative prospective trial. Cancer 120: 2986-2995.

Ng M, Fleming T, Robinson M, Thomson B, Graetz N, Margono C, Mullany EC, Biryukov S, Abbafati C, Abera SF, Abraham JP, Abu-Rmeileh NM, Achoki T, Albuhairan FS, Alemu ZA, Alfonso R, Ali MK, Ali R, Guzman NA, Ammar W, Anwari P, Banerjee A, Barquera S, Basu S, Bennett DA, Bhutta Z, Blore J, Cabral N, Nonato IC, Chang JC, Chowdhury R, Courville KJ, Criqui MH, Cundiff DK, Dabhadkar KC, Dandona L, Davis A, Dayama A, Dharmaratne SD, Ding EL, Durrani AM, Esteghamati A, Farzadfar F, Fay DF, Feigin VL, Flaxman A, Forouzanfar MH, Goto A, Green MA, Gupta R, Hafezi-Nejad N, Hankey GJ, Harewood HC, Havmoeller R, Hay S, Hernandez L, Husseini A, Idrisov BT, Ikeda N, Islami F, Jahangir E, Jassal SK, Jee SH, Jeffreys M, Jonas JB, Kabagambe EK, Khalifa SE, Kengne AP, Khader YS, Khang YH, Kim D, Kimokoti RW, Kinge JM, Kokubo Y, Kosen S, Kwan G, Lai T, Leinsalu M, Li Y, Liang X, Liu S, Logroscino G, Lotufo PA, Lu Y, Ma J, Mainoo NK, Mensah GA, Merriman TR, Mokdad AH, Moschandreas J, Naghavi M, Naheed A, Nand D, Narayan KM, Nelson EL, Neuhouser ML,
Nisar MI, Ohkubo T, Oti SO, Pedroza A, Prabhakaran D, Roy N, Sampson U, Seo H, Sepanlou SG, Shibuya K, Shiri R, Shiue I, Singh GM, Singh JA, Skirbekk V, Stapelberg NJ, Sturua L, Sykes BL, Tobias M, Tran BX, Trasande L, Toyoshima H, van de Vijver S, Vasankari TJ, Veerman JL, Velasquez-Melendez G, Vlassov VV, Vollset SE, Vos T, Wang C, Wang X, Weiderpass E, Werdecker A, Wright JL, Yang YC, Yatsuya H, Yoon J, Yoon SJ, Zhao Y, Zhou M, Zhu S, Lopez AD, Murray CJ, Gakidou E (2014) Global, regional, and national prevalence of overweight and obesity in children and adults during 1980-2013: a systematic analysis for the Global Burden of Disease Study 2013. Lancet 384: 766-781.

National Institute of Health (2010) Cancer Therapy Evaluation Program, Common Terminology Criteria for Adverse Events, Version 4.0, DCTD, NCI, NIH, DHHS June 142010 [Online]. Available at http://evs.nci. nih.gov/ftp1/CTCAE/CTCAE_4.03_2010-06-14_QuickReference 5x7.pdf (last accessed 1 February 2015).

Niraula S, Dowling R, Ennis M, Chang M, Done S, Hood N, Escallon J, Leong W, Mccready D, Reedijk M, Stambolic V, Goodwin P (2012) Metformin in early breast cancer: a prospective window of opportunity neoadjuvant study. Breast Cancer Res Treat 135: 521-530.

Nout RA, Bosse T, Creutzberg CL, Jurgenliemk-Schulz IM, Jobsen JJ, Lutgens LC, Van Der Steen-Banasik EM, Van Eijk R, Ter Haar NT, Smit VT (2012) Improved risk assessment of endometrial cancer by combined analysis of MSI, PI3K-AKT, Wnt/beta-catenin and P53 pathway activation. Gynecol Oncol 126: 466-473.

Renehan A, Tyson M, Egger M, Heller R, Zwahlen M (2008) Body-mass index and incidence of cancer: a systematic review and meta-analysis of prospective observational studies. Lancet 371: 569-578.

Salvesen H, Iversen O, Akslen L (1998) Identification of high-risk patients by assessment of nuclear Ki-67 expression in a prospective study of endometrial carcinomas. Clin Cancer Res 4: 2779-2785.

Salvesen HB, Iversen OE, Akslen LA (1999) Prognostic significance of angiogenesis and $\mathrm{Ki}-67, \mathrm{p} 53$, and p21 expression: a population-based endometrial carcinoma study. J Clin Oncol 17: 1382-1390.

Sarfstein R, Friedman Y, Attias-Geva Z, Fishman A, Bruchim I, Werner H (2013) Metformin downregulates the insulin/IGF-I signaling pathway and inhibits different uterine serous carcinoma (USC) cells proliferation and migration in p53-dependent or -independent manners. PLoS One 8: e61537.

Schuler KM, Rambally BS, Difurio MJ, Sampey BP, Gehrig PA, Makowski L, Bae-Jump VL (2015) Antiproliferative and metabolic effects of metformin in a preoperative window clinical trial for endometrial cancer. Cancer Med 4: 161-173.

Stefansson IM, Salvesen HB, Immervoll H, Akslen LA (2004) Prognostic impact of histological grade and vascular invasion compared with tumour cell proliferation in endometrial carcinoma of endometrioid type. Histopathology 44: 472-479.

Tucker GT, Casey C, Phillips PJ, Connor H, Ward JD, Woods HF (1981) Metformin kinetics in healthy subjects and in patients with diabetes mellitus. Br J Clin Pharmacol 12: 235-246.

Worsley R, Jane F, Robinson PJ, Bell RJ, Davis SR (2014) Metformin for overweight women at midlife: a double-blind, randomized, controlled trial. Climacteric 18: 270-277.

Zaino RJ, Brady WE, Todd W, Leslie K, Fischer EG, Horowitz NS, Mannel RS, Walker JL, Ivanovic M, Duska LR (2014) Histologic effects of medroxyprogesterone acetate on endometrioid endometrial adenocarcinoma: a Gynecologic Oncology Group study. Int J Gynecol Pathol 33: 543-553.

Zakikhani M, Blouin MJ, Piura E, Pollak MN (2010) Metformin and rapamycin have distinct effects on the AKT pathway and proliferation in breast cancer cells. Breast Cancer Res Treat 123: 271-279.

Zakikhani M, Dowling R, Fantus I, Sononberg N, Pollak M (2006) Metformin is an AMP kinase-dependent growth inhibitor for breast cancer cells. Cancer Res 66: 10269-10273.

(c) (1) (2) This work is licensed under the Creative Commons (C) Attribution-Non-Commercial-Share Alike 4.0 International License. To view a copy of this license, visit http:// creativecommons.org/licenses/by-nc-sa/4.0/ 